\title{
CHARLES SOREL, La Maison des Jeux, tome 2, Seconde
}

Journée

\section{Laura Rescia}

\section{(2) OpenEdition \\ Journals}

\section{Edizione digitale}

URL: http://journals.openedition.org/studifrancesi/16339

DOI: 10.4000/studifrancesi.16339

ISSN: 2421-5856

\section{Editore}

Rosenberg \& Sellier

\section{Edizione cartacea}

Data di pubblicazione: 1 juillet 2019

Paginazione: 156

ISSN: 0039-2944

\section{Notizia bibliografica digitale}

Laura Rescia, "Charles sorel, La Maison des Jeux, tome 2, Seconde Journée», Studi Francesi [Online], 187 (LXIII | I) | 2019, online dal 01 juin 2019, consultato il 25 janvier 2021. URL: http://

journals.openedition.org/studifrancesi/16339; DOI: https://doi.org/10.4000/studifrancesi.16339

Questo documento è stato generato automaticamente il 25 janvier 2021.

\section{@() $\Theta \Theta \Theta$}

Studi Francesi è distribuita con Licenza Creative Commons Attribuzione - Non commerciale - Non opere derivate 4.0 Internazionale. 


\title{
CHARLES SOREL, La Maison des Jeux, tome 2, Seconde Journée
}

\author{
Laura Rescia
}

\section{NOTIZIA}

CHARLES SOREL, La Maison des Jeux, tome 2, Seconde Journée, texte établi, présenté et annoté par Marcella Leopizzi, Paris, Champion, 2018, «Sources Classiques» 129, 328 pp.

1 Fausta Garavini aveva scelto, per il suo fondamentale saggio dedicato a Charles Sorel, apparso in italiano nel 1980 e poi pubblicato da Champion nel 1998, proprio il titolo di quest'opera, poco nota anche ai secentisti, e di cui non si disponeva di un'edizione critica completa. Grazie al lavoro di Marcella Leopizzi, che ha già curato il volume relativo alla prima giornata, apparso nel 2017 sempre da Champion, possiamo oggi leggere il testo completo dell'edizione del 1657, con l'apparato variantistico relativo alle due precedenti (1642a e 1642b); le annotazioni e gli indici rendono agevolmente consultabile il volume. Opera ibrida, che muove dai modelli della letteratura cortigiana di intrattenimento, destinata all'honnête homme nell'esercizio della conversazione, questa Maison si indirizza a un pubblico colto, capace di trasformare le capriole intellettuali e logocentriche in un divertimento mai dissociato dall'istruzione. Se le bienséances presiedono al tono generale delle conversazioni tipiche di una mondanità da salon, è nel piacere dell'intelligenza che si declinano tutti i giochi praticati da una piccola comunità aristocratica, tradizionalmente riunita in una dimora di campagna. Lontane dai volgari jeux du hasard, queste ricreazioni si offrono come un valido rimedio contro le amarezze della vita, avverso la malinconia di alcuni membri del gruppo. I personaggi, che si muovono sui due assi della diegesi, potendo esserne sia narratori che protagonisti, dedicano un tempo considerevole alla riflessione metanarrativa: è in questi spazi che ritroviamo la poetica soreliana dell'antiroman, le riflessioni sulla dialettica realtà/finzione, la crociata contro gli errori popolari, tutti aspetti che veicolano, dietro e al di là dell'aspetto ludico, la postura libertina dell'autore. Il tema 
dell'abito, la condanna della superstizione e dei tabù sessuali, della pedanteria e delle istituzioni pedagogiche, della sottomissione della donna all'autorità parentale e maritale, confermano, a distanza di un ventennio, gli orientamenti ideologici già emersi nel Francion. 